\title{
Possible in-service damages of steam generators at VVER-1000 and VVER-1200 NPP units and their impact on long-term operation
}

\author{
Alexander Arzhaev ${ }^{1, *}$, Alexey Arzhaev ${ }^{1}$, Valentin Makhanev ${ }^{1}$, Mikhail Antonov $^{2}$, Anton Emelianov ${ }^{2}$, Aleksander Kalyutik ${ }^{2}$, \\ Yury Karyakin², Maksim Kurakin², Daniil Lyashenko², Kirill Arzhaev ${ }^{3}$, Ilya Denisov ${ }^{3}$ \\ ${ }^{1}$ LLE "SPE “DIAPROK”, Moscow, Russia Federation \\ ${ }^{2}$ Peter the Great St. Petersburg Polytechnic University, Sankt-Petersburg, Russia Federation \\ ${ }^{3}$ ANO “International Nuclear Safety Center", Moscow, Russia Federation
}

\begin{abstract}
Specific features of corrosion-mechanical damages of primary circuit header to steam generator vessel branch welds at VVER-1000 NPPs and their impact on safety and economic efficiency during longterm operation are analysed. Measures to avoid the damages for similar zones of VVER-1200 steam generators are discussed.
\end{abstract}

Keywords. VVER-1000\& VVER-1200 reactor facilities, long-term operation, steam generator, weld of primary circuit header to steam generator branch, corrosion-mechanical damage in operation.

\section{Introduction}

One of serious issues during VVER-1000 NPP operation is damage of primary circuit header (collector) to steam generator (SG) vessel branch welds. The welds under consideration are conventionally indicated as SS-111 for both "hot" and "cold" SG headers.

VVER-1000 NPP Units are significant part of the existing Russian NPP fleet and are also the basis for development of domestic nuclear energy in the future and essential component of nuclear technologies export abroad.

Analysis of the operating experience of the VVER1000 NPP is important both for long-term operation of existing power units and for future effective operation of new NPPs with VVER-1200 and VVER-TOI reactor facilities with a design life of 60 calendar years.

The analysis is of rather high importance due to lack of clearly established root causes of damages in SS-111 zones. It can be used for the VVER-1200 NPP units under construction and under design to clarify the requirements for diagnostics of technical state parameters of the SS-111 zones both at the stages of commissioning and long-term operation.

\section{Operation experience of VVER-1000}

The operation of the VVER-1000 NPPs was not perfect, in particular, because of damages revealed on the primary circuit collectors and forced replacement of a significant amount of SGs at NPP Units in Russia and Ukraine [1]. The next problem area turned out to be the SS-111 zone.
Specific design features of SS-111 zones under consideration are shown in Fig.1 [2]. SG branches connected to headers are oblique ones having long and short forming lines. A typical view of the SS-111 zone "pocket" is shown in the right part of Fig.1.

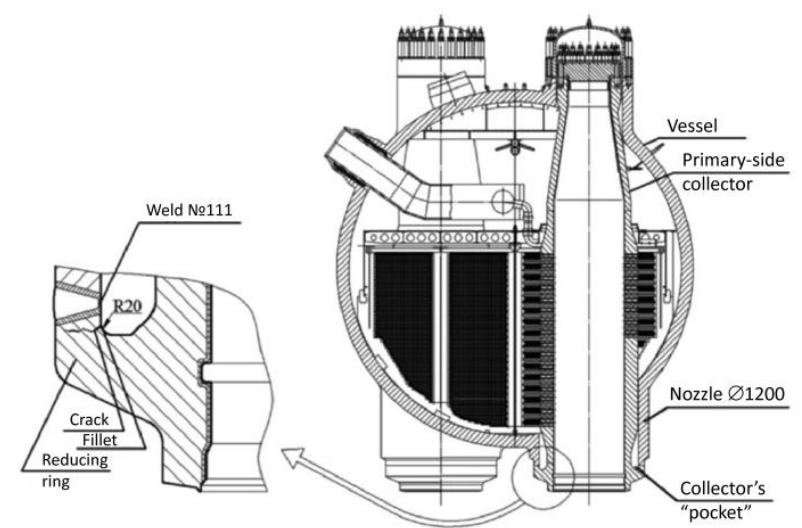

Fig.1. Steam generator PGV-1000M [2]

Damage of SS-111 starts on the inner surface from the "pockets" under corrosion impact of the secondary circuit coolant. Water chemistry parameters inside the "pockets" (Fig.1) may differ for the worse with accumulation of corrosion products and increased content of impurities.

For the first time, SS-111 damage was detected in 1998 at unit No. 5 of Novovoronezh NPP due to a leak. Subsequently, damages of SS-111 welds of "hot" and "cold" SG headers were detected at the Russian NPP units (unit No. 5 of Novovoronezh NPP, units No.No.1, 2 and 4 of the Balakovo NPP), as well as at the

* Corresponding author: arzhaev.alexander@yandex.ru 
Ukrainian NPPs (South Ukrainian NPP and Zaporozhye NPP).

\section{In-service damage mechanism assessment}

Examinations of metal cut from damaged SS-111 zones revealed corrosion-mechanical damage in form of cracks initiating from the inner surface of the "pocket" in contact with secondary side coolant.

Damage in the SS-111 zone of cold SG collector of Kalinin NPP unit No.1 had specific features as long chains of pitting (Fig.2).

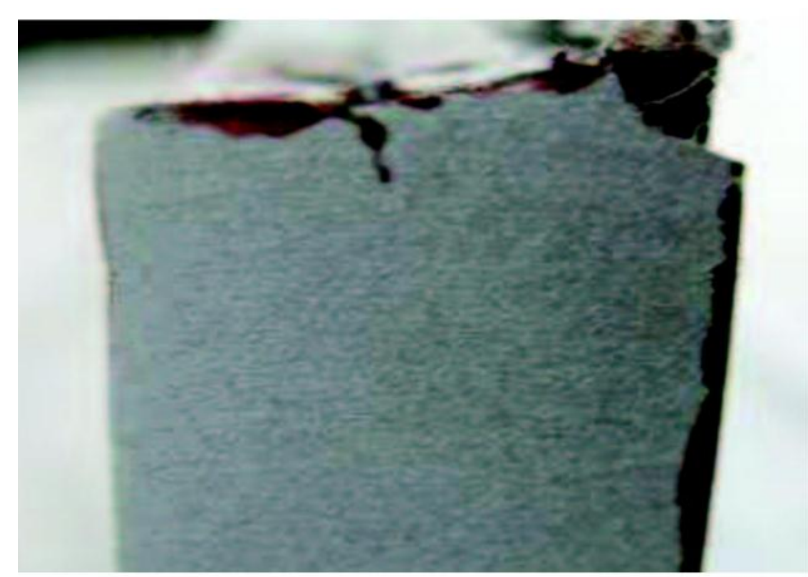

Fig.2. Pitting areas in the SS-111 zone of cold SG collector of Kalinin NPP unit No.1 [3]

Mechanism of crack initiation and growth in the SS111 zones was defined as delayed deformation corrosion cracking $[1,4]$. Studies performed in Ukraine have confirmed the same nature of damage of defective SS111 zones of "hot" and "cold" headers [8]: "comprehensive studies and data obtained earlier suggest that the nature of destruction of welded joints in the steam generators of the South Ukrainian and Zaporozhye NPP is the same, despite the fact that the cracks were formed on the "hot" header in the first case, and on the "cold" - in the second".

In [2] based on results of computational substantiation of strength of the header and its connection zone with the SG branch, using refined threedimensional finite element models and taking into account the significant factors (pressure environments of the first and second circuits; temperature field during facility operation at nominal parameters, loads from piping of the main circulation circuit (MCC)), it was noted "powerful" impact of MCC on the area of damage in combination with improper work of SG supports PG due to their jamming and additional resistance to $\mathrm{SG}$ movement via supports.

In the report of JSC OKB "Gidropress" [6] on the SS-111 zone, it was stated that "the highest level of loading of the zone is realized during hydraulic testing of SG secondary circuit (at yield strength level) and when cooling via blowdown lines, and high loading is also possible during improper operation of the SG supports".
Characteristically, the position of the primary damages in the SS-111 zones of "cold" headers is also close to so-called "MCC line" as for "hot" headers (Fig.3) both on VVER NPP Units of "small" series, and on VVER NPP Units of the project V-320 (according to JSC NPO "CNIITMASH" reports [4, 7]).

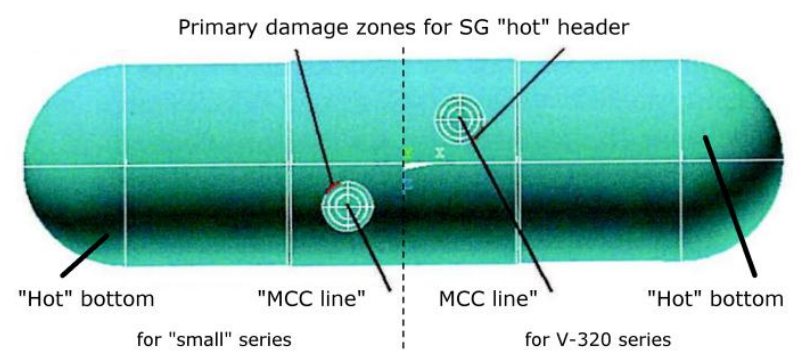

Fig.3. Zones of primary damages for VVER-1000 of "small" series and V-320 series from [8]

The results are consistent with the hypothesis that there is a directed mechanical impact of the MCC piping on the SS-111 zones, which should be considered as the main factor in the formation and growth of primary cracks in the direction of the "MCC line" (Fig.4-6). Fig.4 shows caption comments that are common to Fig.4-6.

Other factors (technology of rolling heat exchange tubes, presence of deposits in the "pockets" of SG, actual parameters of the secondary circuit water chemistry, etc.) should be considered as concomitant, despite their possible influence on crack initiation under delayed deformation corrosion cracking mechanism.
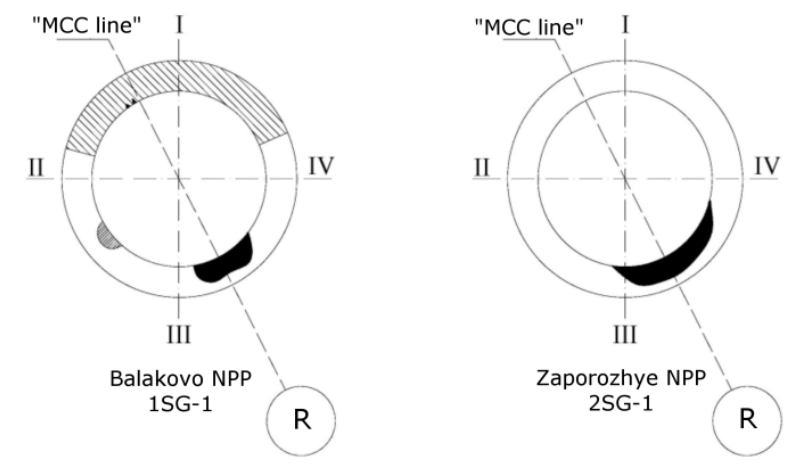

\footnotetext{
- primary damage (1st repair)

- secondary damage (2nd and other repairs)

R - reactor

I - long forming line (FL) of the Ø1200 SG branch

II - FL of the Ǿ1200 SG branch near SG "cold" bottom (Figure 4) III - short FL of the Ǿ1200 SG branch

IV - FL of the Ø1200 SG branch near SG "hot" bottom (Figure 4)

"MCC line" connects centers of reactor and each SG header
}

Fig.4. Zones of primary and repeated defects in SS-111 of VVER NPP Units of the project V-320 ([2]) 


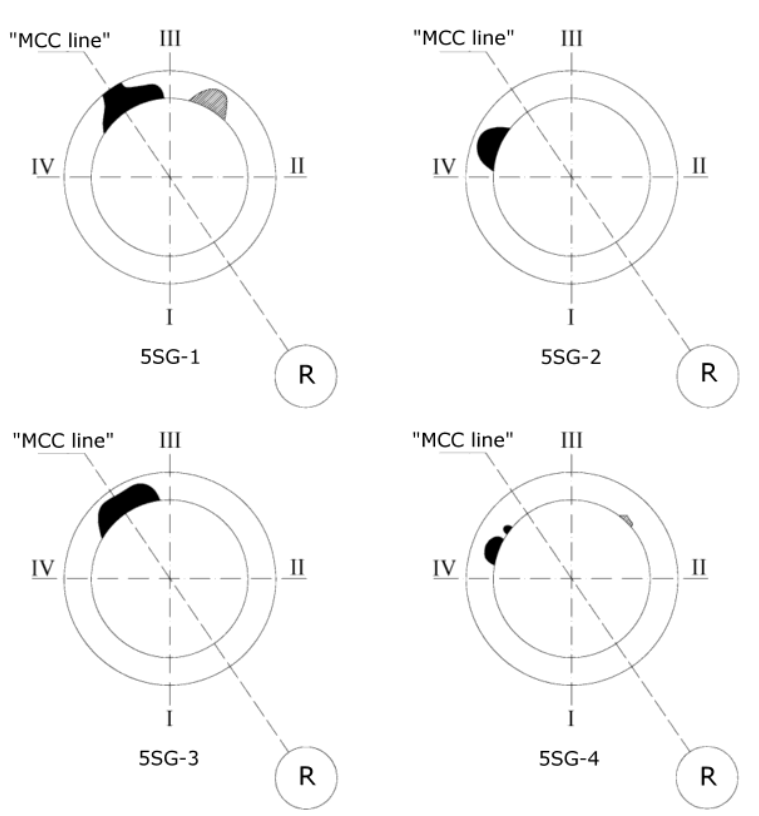

Fig.5. Zones of primary and repeated defects in SS-111 of the unit No. 5 of Novovoronezh NPP ([2])
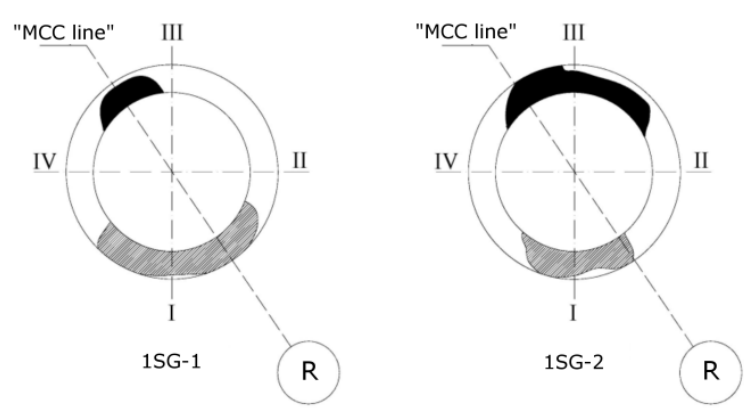

Fig.6. Zones of primary and repeated defects in SS-111 of the unit No. 1 of South Ukrainian NPP ([2])

Layouts of MCC piping of VVER NPP Units of "small" series and VVER NPP Units of the project V320 are shown on Fig. 7 and 8 from [2].

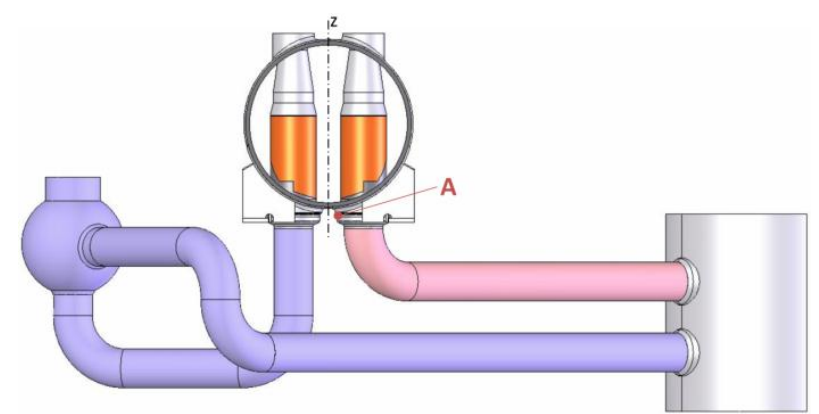

Fig.7. Layout of MCC piping of VVER NPP Units of "small" series ("hot" MCC piping in rose color)

Points A (Fig.7) and B (Fig.8) show maximum loaded zones located near short forming line of SG branches and "MCC line" (Fig.3).

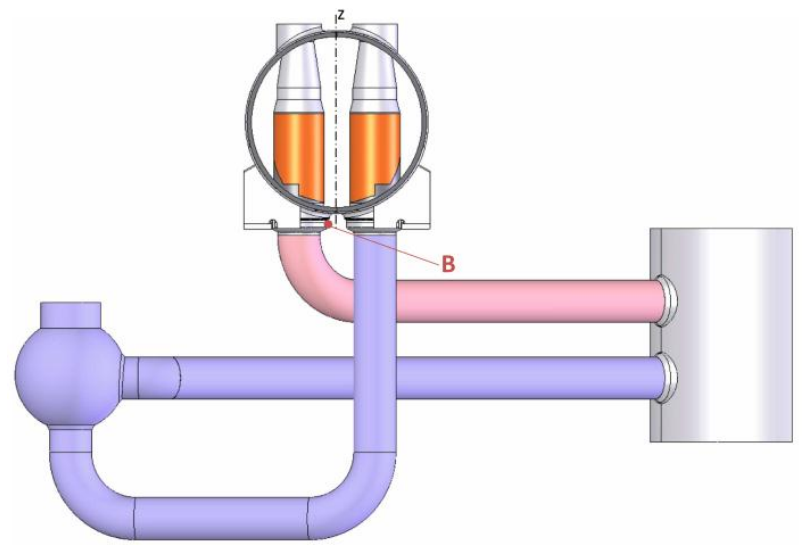

Fig.8. Layout of MCC piping of VVER NPP Units of the project V-320 series ("hot" MCC piping in rose color)

\section{Damage cause analysis}

Additional resistance to SG movement via supports due to their jamming generates extra loads for the SS-111 zones during start-up and shut-down of NPP unit.

Table 1 provides information on repairs of the SS111 zones at all NPP units with VVER-1000 reactor facility according to $[4,6,9]$ : the intense yellow background highlights the primary damage of the SS111 zones of the "hot" headers, and the blue background highlights the "cold" headers. The "+" symbols indicate the number of repeated damages in different years. Information on absence of cracking of the SS-111 zones at several VVER-1000 NPPs was confirmed in the speeches of representatives from Ukraine (Rivne and Khmelnitsky NPPs), Bulgaria (Kozloduy NPP) and the Czech Republic (Temelin NPP) at the WANO MC seminar held in Yerevan (Armenia) in May 2015 [10].

Information on repeated damages of the SS-111 zones are shown in Table 2: the intense yellow background highlights the primary damage of the SS111 zones of the "hot" headers, (the cases of repeated damages are highlighted in light yellow background), and the blue background highlights the "cold" headers. Through-wall damages are marked by " $\boldsymbol{\Delta} "$ symbols. Negative assessment of the dynamics of damage in 2010-2014 is too pessimistic, since many of these damages are repeated, that is, after the use of repair technology with through-thickness metal removal and subsequent volume filling by welding. However, the repeat leakages in almost the same place (Fig.4) of the 5SG-1 hot collector at unit No. 5 of Novovoronezh NPP, first $\sim 9$ years after the replacement of the $S G$, and then $\sim 15$ years after the repair of this defective zone by welding, show that the main factors that led to throughwall damage were not identified and eliminated during the period from 1998 to 2013.

In [11], it is erroneously stated that the time before appearance of through-thickness defect in the metal of the 5SG-1 hot collector at unit No. 5 of Novovoronezh NPP was 24 years. 
Table 1. Information on repairs of the SS-111 zones at all NPP units with VVER-1000

\begin{tabular}{|c|c|c|c|c|c|c|c|c|c|}
\hline \multirow{2}{*}{ NPP } & \multirow{2}{*}{ Unit } & \multicolumn{2}{|c|}{ SG-1 } & \multicolumn{2}{|c|}{ SG-2 } & \multicolumn{2}{|c|}{ SG-3 } & \multicolumn{2}{|c|}{ SG-4 } \\
\hline & & "Hot" & "Cold" & "Hot" & "Cold" & "Hot" & "Cold" & "Hot" & "Cold" \\
\hline Novovoronezh NPP & 5 & ++++ & & + & & + & & ++ & \\
\hline \multirow[t]{4}{*}{ Kalinin NPP } & 1 & & & & & & + & & \\
\hline & 2 & & & & & & & & \\
\hline & 3 & & & & & & & & \\
\hline & 4 & & & & & & & & \\
\hline \multirow[t]{4}{*}{ Balakovo NPP } & 1 & ++ & & & & & & & + \\
\hline & 2 & & & ++ & & & & & \\
\hline & 3 & & & & & & & & \\
\hline & 4 & & + & & & & & & \\
\hline \multirow[t]{3}{*}{ Rostov NPP } & 1 & & & & & & & & \\
\hline & 2 & & & & & & & & \\
\hline & 3 & & & & & & & & \\
\hline \multirow[t]{3}{*}{ south Ukrainian NPP } & 1 & ++ & & ++ & & & & & \\
\hline & 2 & & & & & & & & \\
\hline & 3 & * & $* *$ & & & & ** & & \\
\hline \multirow[t]{6}{*}{ Zaporozhye NPP } & 1 & & & & & & & & \\
\hline & 2 & + & + & & + & & & & \\
\hline & 3 & & & & & & & & \\
\hline & 4 & & & & & + & & & \\
\hline & 5 & & & & & & & & \\
\hline & 6 & & & & & & & & \\
\hline
\end{tabular}

Note: at Unit No.3 of South Ukrainian NPP sub-surface flaws were revealed by In-service Inspection [13] and repaired in $2012\left({ }^{*}\right)$ and $2014\left({ }^{* *}\right)$

Table 2. Information on repeated damages of the SS-111 zones

\begin{tabular}{|c|c|c|c|c|c|c|c|c|c|c|c|c|c|c|c|c|c|c|c|c|}
\hline NPP & NoSG & Replaced & 1998 & 1999 & 2000 & 2001 & 2002 & 2003 & 2004 & 2005 & 2006 & 2007 & 2008 & 2009 & 2010 & 2011 & 2012 & 2013 & 2014 & 2015 \\
\hline \multirow{4}{*}{$\begin{array}{c}\text { Novovoronezt } \\
\text { NPP }\end{array}$} & $5 \mathrm{SG}-1$ & \begin{tabular}{|l|l|}
19893 \\
\end{tabular} & $\Delta$ & & & & & & & & & & & & & & & $\Delta$ & & \\
\hline & $5 S G-2$ & 19873 & & & & & & & & & & & & & & & & & & \\
\hline & 5SG-3 & 19903 & & & & & & & & & & & & & & & & & & \\
\hline & 5SG-4 & 19893 & & & & & & & & & & & & & & & & & & \\
\hline Kalinin NPP & 1SG-3 & no & & & & & & & & & & & & & & & & & & \\
\hline \multirow{4}{*}{ Balakovo NPP } & 1SG-1 & 19903 & & & & & & & & & & & & & & & & & & \\
\hline & 1SG-4 & 19903 & & & & & & & & & & & & & & & & & & \\
\hline & 2SG-2 & 20003 & & & & & & & & & & & & & & & & & & \\
\hline & $4 \mathrm{SG}-1$ & no & & & & & & & & & & & & & & & & & & \\
\hline \multirow{2}{*}{\begin{tabular}{|c|} 
South \\
Ukrainian NPP
\end{tabular}} & 1SG-1 & 19893 & & & & & & & & & & & & & & & & & & \\
\hline & 1SG-2 & 198933 & & & & $\Delta$ & & & & & & & & & & & & & & \\
\hline \multirow{3}{*}{$\begin{array}{c}\text { Zaporozhye } \\
\text { NPP }\end{array}$} & 2SG-1 & 19903 & & & & & & & & & & & & & & & & & & \\
\hline & $2 \mathrm{SG}-2$ & 19903 & & & & & & & & & & & & & & & & & & \\
\hline & $4 \mathrm{SG}-3$ & no & & & & & & & & & & & & & & & & & & \\
\hline
\end{tabular}

Note: $\boldsymbol{\Lambda}$ - damage revealed by leak.

As can be seen from table 1, the damage of the SS111 zones affects mainly the group of SGs replaced at NPP units due to damage of the headers and/or due to plugging of the heat exchange tubes over the limit. Of the 15 damaged units, only 3 were damaged on SGs operating on the units since installation. Information on SG replacements is provided in the report [12] based on several sources [1, 13-14].

When replacing the SGs on an NPP unit in operation, one of the welded joints SS-111 of "hot" or "cold" header becomes the closing one, whereas when installing SG to MCC at construction stage both welded joints SS111 of the "hot" and "cold" headers to Dn850 pipelines are never the closing ones.

Thus, it seems acceptable to assume that part of the SGs was installed with the presence of implicit mounting preload during replacement (tables 1 and 2), which was not detected after repair and was not recorded in the reporting documentation. A similar hypothesis assumed presence of implicit mounting preload during the installation of part of the SGs in the MCC on newer blocks also seems realistic, since table 1 shows that the percentage of damaged SGs (from the number of not replaced) is significantly lower than among the sample of replaced SGs.

In the future, implicit mounting preload during the installation/repair could lead to restrictions (jamming) when SG moving via supports, taking into account the specifics of design solutions for MCC of VVER NPP Units of "small" series, and VVER NPP Units of the project V-320.

Therefore, the main cause of primary cracks in the SS-111 zones is the interaction of several factors that were excluded earlier from the analysis of the causes of damage in [15], namely: «4.1 Preload of the Du850 MCC piping during the replacement of the SGs», «4.3. Jammed roller and/or ball bearing supports of SG and/or $\mathrm{MCC}$, «4.4 SG jammed for other reasons», which can be combined into a common cause: "shortness (jamming) of SG displacement on the supports". The crack growth rates depend to a significant extent on water chemistry inside the SG "pockets".

\section{Conclusion}

So primary damages in the SS-111 zones did not lead to extensive propagation along the circumferential weld 
perimeter, and the correlation of their location with the "MCC line" indicates the role of mechanical loads in the process of damage that does not pose a threat of complete break. However, for long-term cost-effective operation of the SG, it is necessary to improve load monitoring system for the SS-111 zone (for early detection of prerequisites for cracking initiation) and SG maintenance and repair/replacement technology.

Measures to monitor the thermomechanical loading of the SS-111 zone (especially after weld repair or/ and SG replacement) will allow to get an early warning for NPP personnel about non-project loading and the need for compensative actions in the form of an extraordinary preventive maintenance of SG supports and more frequent ISI of the SS-111 zone.

It should be noted that in-service damages of the SS111 zone lead to decrease of NPP unit availability rather than safety. Operation experience should be also taken into account for VVER-1200 NPP Unit design to avoid in-service damages of the SS-111 zone during long-term operation.

The reported study was funded by RFBR according to the research project № 19-07-00455.

\section{References}

1. B.I. Lukasevich, N.B. Trunov, Yu.G. Dragunov, S.E. Davidenko, Steam generators of VVER reactor plants for nuclear power plants (2004, in Russian).

2. N.B. Trunov, S.A. Kharchenko, N.F. Korotaev, S.L. Lyakishev, Results of studies of metal fracture causes in the area of primary collector-to-steam generator vessel welding and development of corrective measures, Proceedings of the 8th International seminar of horizontal steam generators, (2010, in Russian).

3. V.D. Khodakov, New technologies of repair of equipment and pipelines of NPP with the use of welding: 2005-2008 (in Russian).

4. A.V. Dub, A.N. Razygraev, N.P. Razygraev, A.N. Ryabov, I.L. Kharina, Technology of NDT of primary collector-to-steam generator vessel welding of the steam generator PGV-1000 (Weld No111) and defects in it: systematization and nature, Proceedings of the 12th international conference on "Material issues in design, manufacturing and operation of nuclear power plants equipment" (2012, in Russian).

5. L.S. Ojigov and etc., Peculiarities of damage of welded joints №111 in steam generators of power units of WWER-1000, MNTK-2013: proceedings of the 8th Conference "Safety Assurance of NPP with VVER" (2013, in Russian).

6. JSC OKB "GIDROPRESS", Evaluation of the effectiveness of measures to prevent damage to welds No.111 at VVER-1000 NPP steam generators, Speaker - S.A. Kharchenko (2015, in Russian).

7. A.N. Razygraev, CNIITMASH experience in ultrasonic testing, repair and materials science support of the collector welding unit to the steam generator of the VVER-440 reactor unit, Working meeting of the WANO Moscow center (2015).

8. A.V. Bogachev, V.P. Semishkin, A.O. Nagorny, A.V. Merkun, D.B. Muravin, R.Yu. Zhukov, E.A. Frizen, Life management in conditions of timedelayed deformational corrosion cracking, Heavy engineering, 7-8 (2017, in Russian).

9. SEC NRS, Possible causes and factors contributing to damage to the welding unit of the coolant collector to the steam generator body at a nuclear power plant with a VVER-1000 reactor according to the results of research by industry enterprises. Part 1: Possible causes, Speaker - V.S. Rubtsov (2015, in Russian).

10. WANO MC, Aide-Memoire on the results of the workshop at the Armenian NPP, Working meeting of the WANO Moscow center (2015).

11. V.P. Povarov. Analysis of damaged welds No.111 in the PGV-1000 steam generator and damage repair proposals, Nuclear Energy and Technology, 1, 1 (2015).

12. E.G. Adadurov, M.I. Antonov, A.I. Arzhaev, S.I. Velikodnij, Yu.E. Karyakin, V.O. Makhanev, M.A. Podlatov, About operability of weld joints of primary circuit headers with steam generator branches of VVER-1000 and VVER-1200 Reactors, Report at the 5th International scientific and technical conference JSC “Atomtechenergo" (2018, in Russian).

13. A.A. Kadnikov, Optimization of the complex of works on replacement of steam generators of nuclear power units with VVER, dissertation for the degree of candidate of technical sciences: 05.14.03 (2009, in Russain).

14. A.V. Gerasimov, Modernization of the technological process for replacing PG units with VVER-1000, MNTK-2012: proceedings of the 8th Conference "Safety, efficiency and economics of nuclear power industry" (2012, in Russian).

15. A.F. Getman, A.I. Usanov, B.I. Lukasevich, A.A. Tutnov, L.A. Pasmanik, V.A. Smirnov, A.V. Kamyshev, Reasons of PGV-1000 welded joints no.111 sdamages and proposals on its elimination, Proceedings of the 8th International seminar of horizontal steam generators (2010, in Russian). 